\title{
Branding: a percepção da marca no relacionamento entre uma Instituição de Ensino Superior e seus acadêmicos.
}

Branding: brand perception in the relationship between a Higher Education Institution and its academics.

EICH, Edilene; Designer, especialista em Design e Gestão de Marca: Branding; Unochapecó edi_eich@hotmail.com

SCHWENGBER, Eduardo C.; Designer Industrial, mestre em Design, Educação e Inovação. Unoesc.

eduardocsdesign@yahoo.com.br

\section{Resumo}

Considerando o atual cenário educacional no que se refere à retenção de alunos nas Instituições de Ensino Superior (IES), o objetivo deste estudo foi entender os motivos pelos quais os acadêmicos permanecem em determinada IES, afim de refletir sobre a retenção discente, com atividades de extensão, pós-graduações, lembrança e indicação da marca. Para tanto, realizouse uma pesquisa descritiva, com abordagem qualitativa dos dados, por meio de levantamento, visto que os dados primários foram coletados com a utilização de um questionário estruturado com escala Likert. A amostra por conveniência compreendeu 40 acadêmicos de ensino superior. A partir dos resultados obtidos foi possível perceber como acontece a relação acadêmico/instituição verificando uma constante evolução, estrutural e de ensino, primando pelo bom relacionamento pessoal e atendimento, aliado a uma excelente estrutura, em um ambiente saudável ao aprendizado.

Palavras-chave: Branding; Instituição de Ensino Superior (IES); Retenção acadêmica.

\begin{abstract}
Taking into account the current educational scenario regarding the retention of students in Higher Education Institutions - HEI, the objective of this study was to understand the reasons why the students remain in a certain institution, in order to reflect about student retention, with extension activities, post-graduation, memory and indication of the brand. For that, a descriptive research was carried out, with qualitative approach of the data, by means of survey, since the primary data were collected with the use of a questionnaire structured with Likert scale. The convenience sample comprised 40 higher education academics.Therefore, it was possible to notice how the academic/institution relationship happens, verifying structural and educational constant evolution, giving priority to the good personal relationship and attendance, together with an excellent structure, in a healthy learning environment.
\end{abstract}

Keywords: Branding; Higher Education Institution (HEI); Academic retention. 


\section{INTRODUÇÃO}

A marca é considerada indispensável para qualquer tipo de organização, independente de sua atividade no mercado (RAMEZANALI; SOUZA; SILVEIRA, 2014). Nesse sentido, este estudo objetiva realizar uma análise sobre a percepção acerca da marca de uma Instituição de Ensino Superior (IES) localizada no oeste do Estado de Santa Catarina, a fim de refletir sobre como acontece o relacionamento acadêmico/instituição, buscando fortalecer os vínculos e conferir como a marca é percebida. As instituições de ensino visam compreender os motivos pelos quais os acadêmicos permanecem ou saem da IES e como percebem a marca no reflexo de suas ações.

Diante deste contexto, destaca-se a seguinte questão que norteia o desenvolvimento desta pesquisa: entender os motivos pelos quais os acadêmicos permanecem em uma Instituição de Ensino Superior e suscitar sobre sua retenção para posteriores ações e relações, como atividades de extensão, pós-graduações, capacitações, bem como, a indicação da marca.

Os objetivos específicos que o estudo propõe são: i) pesquisar conceitos e bases da estruturação da marca da IES, no sentido da sua apresentação perante os acadêmicos e ao público externo; ii) perceber as necessidades e adjetivos que fazem com que os acadêmicos, optem pela IES e se relacionem com a mesma.

Esse processo de retenção dos alunos será estudado junto de uma identificação da imagem que a marca gera, para que esse processo aconteça de forma benéfica e qualitativa para o acadêmico, que busca qualificação profissional e para a IES, que almeja trazer o melhor serviço e atendimento para uma boa imagem da marca, em uma construção conjunta.

Entendendo o que mantém um acadêmico durante o período da realização do seu sonho de graduação, é preciso aprofundar o conhecimento sobre seus motivos de permanência e de externalizar o que passaram nesta, para que o vínculo futuro também seja efetivo e de bons resultados. Esse vínculo pode ser encontrado tanto na boa impressão da marca, como na efetivação de outros serviços na IES, o que remete há uma boa construção da marca e satisfação para com essa.

De acordo com Vieira, Troccoli e Silva (2011), novos desafios foram postos aos gestores das IES, pois avaliar as percepções dos acadêmicos em relação aos serviços prestados pela IES tornou-se uma tarefa fundamental para a gestão. A partir desta avaliação as IES podem tomar decisões estratégicas e operacionais por meio da perspectiva dos clientes, no caso os acadêmicos, estes que influenciam o nível de qualidade e a satisfação para com os serviços prestados.

A contribuição do estudo é vista nos argumentos de Vieira, Troccoli e Silva (2011), pois salientam que o desafio para as IES é a utilização do marketing em um mercado competitivo, com vistas a atingir seus objetivos sem perder a sua finalidade. Nesse sentido, ao buscar o entendimento das percepções de qualidade e da satisfação dos acadêmicos, as IES procuram melhorar seus serviços.

Portanto, é essencial compreender as mudanças no comportamento do público alvo, além de pesquisar as tendências no que se refere a modelos de ensino e percepção da motivação da atual geração e de seus desejos ao entrar em uma faculdade, tendo em vista que estudantes de várias regiões, advindos de diversas culturas e com ideias diferentes e complexas, mas que sonham com um futuro brilhante no que se refere a escolha da profissão e como ocorrerá todo esse processo e essa relação com a faculdade. Diante disso, Almeida e Soares (2004, p. 82) 
afirmam que:

Os jovens que ingressam na universidade confrontam-se com uma série de desafios pessoais, interpessoais, familiares e institucionais que merecem uma análise mais atenta pelas autoridades e serviços acadêmicos com maiores responsabilidades na percepção e apoio aos estudantes.

Palácio, Meneses e Pérez (2002) partem do princípio que a imagem da marca tem influência considerável no comportamento de consumidores, podendo-se considerar que a imagem é um fator de decisão ao se adquirir produtos ou serviços de organizações. A imagem atrai públicos internos e externos, atuais e potenciais. A influência da imagem no aumento das vendas e no fortalecimento da lealdade com a marca é notório. Portanto, é lógico que, hoje em dia, imagem da marca é de grande importância em empresas que visam lucro ou não.

E é essa intimidade, relação e percepção que este estudo busca compreender para que a imagem da marca seja positiva e o que acontece nesse período de graduação aconteça de forma benéfica para ambos os interessados, numa construção do conhecimento, marca e relacionamento, duradoura.

\section{REFERENCIAL TEÓRICO}

Com vistas a sustentar o desenvolvimento e resultados desta pesquisa, apresentam-se inicialmente os aspectos relacionados à gestão da marca, uma explanação sobre a importância do Branding nesse entendimento e na sequência, discorre-se sobre a comunicação organizacional na questão do ensino superior e na retenção de acadêmicos.

Para compreender inicialmente como se denomina uma marca, Martins (2000) aponta que: "Uma boa marca é capaz de atrair e reter o consumidor para o seu produto ou serviço, retendo-o enquanto a engrenagem estiver funcionando com equilibrio e eficiência;" para isso, aponta-se uma pesquisa sobre elementos essenciais para uma gestão da marca de prestação de serviços de Ensino. Além disso, o fortalecimento da marca é considerado uma ação estratégica que pode requerer o desenvolvimento de ações positivas, bem como, a consolidação do posicionamento da marca juntamente aos consumidores-alvo (KELLER, 2009), que neste estudo são os acadêmicos das IES.

\section{GESTÃO DE MARCA E BRANDING EDUCACIONAL}

Há algum tempo atrás o posicionamente de uma marca e a tangibilidade de seu valor, era algo distante e pouco conhecido no mundo do design e do marketing, que norteiam a atual colocação de uma marca no mercado. A partir do momento em que o posicionamento foi adicionado ao vocabulário do marketing, a gestão da marca passou a ganhar atenção das empresas, bem como do setor educacional, especificamente, as IES.

De acordo com Ramezanali, Souza e Silveira (2014, p. 79), o interesse dos gestores das IES "pelo marketing educacional, principalmente na última década, parece ser consequência natural do aumento da complexidade da gestão dessas organizações e dos desafios que estão enfrentando atualmente". Melo (2014, p. 95) aborda que: "o branding diz respeito exatamente ao posicionamento da empresa no mercado".

Nesse sentido, as organizações buscam constantemente o desenvolvimento de uma marca forte, com identidade própria, que as diferenciem dos concorrentes, com o intuito de fazer face ao mercado competitivo (RAMEZANALI; SOUZA; SILVEIRA, 2014). Contudo, a 
marca pode interferir de maneira positiva nessa diferenciação, minimizando assim, a incerteza do consumidor na escolha de bens e serviços (SCHARF et al., 2013).

Para tanto, gerenciar uma marca de serviços prestados a educação, foco nesta pesquisa, requer estratégias e estudos de análise para que esta seja lembrada pelo consumidor, de forma que:

A congruência entre a identidade e a imagem torna-se assim, um desafio crítico para as universidades uma vez um conceito de marca consistente é muitas vezes usado para um mercado alargado. De acordo com a teoria institucional, uso internacional de extensões de marca deve igualmente assegurar uma legitimidade na mente dos clientes (FARRUGIA;LANE, 2013).

Para bem representar em números o poder geral das marcas, alguns estudos e pesquisas comprovam que um consumidor satisfeito tem o poder de atrair, em média, mais seis novos consumidores, em compensação os insatisfetios têm o poder de decretar a morte de qualquer negócio, arastando pelo menos 14 potenciais consumidores a não mais usar de determinada marca mal empregada. Vieira, Troccoli e Silva (2011) complementam esta questão da satisfação ressaltando que uma IES para ser bem sucedida, deve lidar de maneira eficaz com seus públicos e gerar altos níveis de satisfação.

Dessa maneira, todos os ambitos da gestão da marca devem ser analisados e de acordo com Rodrigues (2006, p. 5):

Selecionar e combinar atributos tangíveis e intangíveis para diferenciar o produto, serviço ou a corporação de uma mesma maneira atrativa, significativa e convincente [...], porque ao adquirir um produto, o consumidor não compra apenas um bem ou serviço, mas, os valores que estão contidos na marca

O branding ou o gerenciamento estratégico da marca se baseia em uma série de ações de gestão, que, como ressalta Garcia et al. (2006, p. 18) "a marca pode ser entendida como um verdadeiro relacionamento entre empresa e consumidor, que gera vantagem competitiva para as empresas e determina as decisões dos consumidores" e essa relação no âmbito das IES não é diferente, pois em um mercado tão competitivo quanto a indústria do conhecimento, Rodrigues (2006) confirma que a diferenciação está mesmo na marca, e essa marca deve expressar um relacionamento muito intenso com os seus alunos. Relacionamento que vai gerar vantagens competitivas a tal ponto que o produto ou serviço vai se vender sozinho.

É importante observar o público-alvo em todos os aspectos, todo o processo de desenvolvimento da marca e a introdução de seu conceito juntamente com a função comercial, devem respeitar a cultura e organização da comunidade onde o consumidor estiver inserido.

Para compreender o que acontece nas IES, como enfoque de vínculo com o seu público, é preciso entender como a gestão dessa identidade e marca, ao tratar do branding, desempenha o seu papel na construção da relação entre a IES e as principais partes interessadas, bem como aumentar a exposição da IES na comunidade que está inserida (BENEKE, 2011). Para tanto, Vieira, Troccoli e Silva (2011) destacam que as IES que respondem ao mercado, não apenas realizam um levantamento sobre a satisfação atual dos clientes, mas também analisam suas necessidades e preferências com vistas a encontrar maneiras de melhorar os serviços prestados. Nesse sentido, a boa imagem da marca, a gestão de uma marca educacional, é fruto da comunicação que se estabelece intencionalmente ou não, entre a IES e o seu público (alunos, famílias, empresas, etc.), ou seja, a comunidade em que está inserida. Em uma IES, a 
diversidade de atores institucionais e sociais diretamente envolvidos com a IES obriga a se pensar em públicos, como sugere Bueno (2002).

Baldissera (2001) acrescenta que é preciso conhecer a atuação do mercado e como a organização posiciona-se perante sua concorrência. Para ela, "[...] a definição de uma boa estratégia está diretamente relacionada à análise do ramo (segmento) de atuação e à determinação da posição exata da empresa no âmbito de sua competência principal" (BALDISSERA, 2001, p. 4). Para tanto, "as IES devem adotar estratégias destinadas a promover e manter a sua posição de mercado" (RAMEZANALI; SOUZA; SILVEIRA, 2014, p. 82).

Na realidade, o que uma universidade apresenta (em sua comunicação, o que as pessoas falam dela, sua comunicação boca a boca, e suas ações que lhe caracterizam uma personalidade) depende da qualidade que oferece na sua função educativa, sendo que criará uma lembrança de marca que determinará valor e vai gerar expectativa sobre a IES (GONÇALVES; GARRIDO; DAMACENA, 2010). Somente assim, uma IES deve construir uma boa reputação e poderá investir e realinhar os seus diferenciais de acordo com o que o consumidor percebe como necessidade.

Cobra e Braga (2004, p. 40) afirmam que "não basta mais a IES anunciar que tem excelência no ensino, instalações modernas, tradição e corpo docente intitulado. Nada disso é visto como diferencial competitivo pelo cliente, mas sim como pré-requisito mínimo para ocupar um lugar no mercado".

$\mathrm{Na}$ atualidade, o que agrega valor e impulsiona a escolha de um produto ou serviço, com nível tecnológico e de qualidade semelhantes, são os valores subjetivos (emocionais) que estão relacionados intimamente a esta marca. Esses valores precisam ser encarados pela organização como uma ideologia, um pensamento comum a todos que estão ligados à IES.

Para sanar e tentar evoluir nesses impasses e problemas percebidos no decorrer da gestão, os atributos de uma marca de ensino superior terão que refletir valor para o consumidor, e conforme Braga (2005, p. 67):

Quanto mais familiar lhe é um produto ou serviço, maiores serão as chances de você adquiri-lo. Quanto mais presente uma marca estiver no seu dia-a-dia, maior será seu vínculo afetivo com ela.

Para isso três fatores críticos precisam ser atendidos: - O relacionamento da escola com o cliente não pode ser intrusivo, evasivo nem constrangedor. O relacionamento precisa estar de acordo com a conveniência do cliente, não da escola. Para isso, aplicam-se as estratégias do marketing de permissão. - Todo contato da escola com o cliente deve agregar valor ou ser relevante para o cliente. Contatos contínuos sem valor agregado comprometem a imagem da escola e deterioram o vínculo relacional.

- Para que o famoso slogan "você conhece, você confia" seja realmente válido, é preciso que as ações de relacionamento feitas para tornar o produto conhecido sejam sustentadas por um suporte eficiente. Prometer e não cumprir é corrosivo para as estratégias de relacionamento. Não adianta um produto ou instituição ser conhecido (ter familiaridade) sem ter credibilidade.

Afinal, uma vez que a IES seja percebida como promotora de formação superior, esta poderá conquistar com mais facilidade "fatias" desse mercado de ensino superior tão disputado, mas antes tem de estar fortemente caracterizada como IES.

Guimarães (2011) ressalta que o importante de uma essência de marca é que esta seja um norte atraente e inspirador, e isto acontece no momento em que o acadêmico ingressa em uma 
IES, seja caminhando pelo campus, entrando em um determinado prédio, na aula ministrada pelo docente em sala ou, ainda, no impacto causado pelas ações estratégicas de comunicação e marketing.

De acordo com este contexto, Silva e Vilaça (2008, p. 10) relatam que "um processo educacional só se torna legítimo quando realizado nos dois sentidos". Para isso, é necessário se ter em mente que a comunicação ganha força quando se entende que, paradoxalmente, as pessoas ainda privilegiam o contexto humano, ou seja, as tecnologias não são capazes de promover a interação, por mais que se apresentem como dotadas dessa competência.

Diante do contexto supracitado, vale ressaltar que a comunicação é uma ferramenta fundamental para a garantia de sobrevivência das IES. O conhecimento proporcionado pelas mesmas deve ser gerido por meio de uma comunicação que garanta um maior grau de harmonia entre os seus colaboradores, proporcionando assim, maior segurança e confiabilidade em relação aos seus serviços prestados e a imagem de marca gerada.

\section{PROCEDIMENTOS METODOLÓGICOS}

A partir do objetivo de perceber e refletir sobre a imagem da marca e de como determinadas ações influenciam no relacionamento e lembrança da marca, por quem está dentro da IES, realizou-se um estudo descritivo quanto aos conceitos que norteiam o estudo da gestão de marca, do branding e da atual situação das instituições de ensino. Para complementar e dar embasamento, foi também adotado neste estudo, uma pesquisa de levantamento, a partir da utilização de um questionário como técnica de coleta de dados com vista a responder a questão de pesquisa. Já no tocante à abordagem do problema de pesquisa, este estudo classifica-se como qualitativo, visto que serão verificadas as estratégias praticadas, ao que se percebe no posicionamento da marca no âmbito de gestão de marca, comunicação e percepção para retenção de alunos. Para tanto, o delineamento desta pesquisa é descritivo, de levantamento e por meio de uma abordagem qualitativa dos dados.

A população da pesquisa compreendeu acadêmicos de IES. A amostra foi escolhida de maneira intencional não probabilística constituiu-se de acadêmicos de uma IES do oeste do Estado de Santa Catarina, e o questionário foi enviado aos acadêmicos de todos os semestres, para melhor construção de uma posição e verificação de resultados. Deste modo, a amostra do estudo foi composta por 40 acadêmicos de todos os cursos da Instituição que responderam ao questionário de forma voluntária, a fim de elencar dados sobre seu processo de escolha e sua visão sobre a identidade da marca, percebendo elementos que o retém na IES, permitindo a investigação sobre os motivos que possibilitam a existência de barreiras na comunicação e nos processos. Esta técnica de amostra, de acordo com Malhotra (2006) se baseia no julgamento pessoal do pesquisador, por meio da acessibilidade dos dados.

Quanto ao procedimento de coleta de dados primários, adotou-se a forma de questionário. O questionário foi estruturado com perguntas predominantemente fechadas e com afirmações baseadas no escalograma de Likert (MALHOTRA, 2001; HAIR, 2005). Para tanto, o questionário elaborado teve base em questões utilizando-se uma escala Likert de cinco pontos: (0) Não sei; (1) Discordo totalmente; (2) Discordo; (3) Concordo e (4) Concordo plenamente, perguntas descritivas e de múltipla escolha. O questionário compreende três partes: i) perfil do respondente; ii) desenvolvimento do projeto para retenção de alunos e iii) Questionário descritivo. Estas partes abordam as variáveis analisadas na presente pesquisa. Este questionário foi elaborado a partir da necessidade de se compreender o relacionamento entre acadêmicos e a IES, bem como perceber os pontos falhos, para posteriores ações. .... 
O instrumento de coleta de dados foi aplicado nos meses de dezembro de 2016 e janeiro de 2017 por meio de questionário online, elaborado a partir do GoogleDocs e direcionado à acadêmicos de uma IES no oeste catarinense. As respostas do questionário foram organizadas em planilhas eletrônicas de excel, gráficos e voltadas à análise textual dos dados.

Deste modo, para os procedimentos de análise dos dados coletados por meio do questionário, a técnica empregada foi a análise de conteúdo das respostas, visto que inicialmente efetuou-se a descrição textual dos resultados obtidos nas 15 perguntas fechadas (quantitativas), e nas 5 perguntas abertas (qualitativas), em suma, resultados, quanti/qualitativos e posteriormente analisou-se estes resultados a partir dos objetivos proposto para a consecução deste estudo.

Assim, a partir da análise do material dessa amostra é possível compreender quais as reais necessidades do público alvo e perceber como uma IES é vista perante os seus acadêmicos e público consumidor. Por fim, ressalta-se que neste trabalho, preservou-se a identidade dos respondentes e da IES.

\section{APRESENTAÇÃO E ANÁLISE DOS RESULTADOS}

Partindo do pressuposto de que a comunicação interna de uma IES, constitui-se como uma ferramenta de melhoria e crescimento, proporcionando uma melhor imagem tanto para o seu público interno quanto externo, os resultados da pesquisa realizada mostraram a necessidade de se compreender essa comunicação e para tanto, é preciso compreender que, conforme Frohlich e Stensaker (2010), a história e a identidade organizacional da IES desempenham um papel muito importante na elaboração de estratégias e de recrutamento de estudantes. As IES devem adotar estratégias destinadas a promover e manter a sua posição de mercado.

$\mathrm{Na}$ realidade, o que uma universidade apresenta (em sua comunicação, o que as pessoas falam dela, sua comunicação boca a boca, e suas ações que lhe caracterizam uma personalidade) depende da qualidade que oferece na sua função educativa, sendo que criará uma lembrança de marca que determinará valor e vai gerar expectativa sobre a IES (GONÇALVES; GARRIDO; DAMACENA, 2010).

Os levantamentos da pesquisa apontam, na primeira etapa do questionário que identifica o público entrevistado, que a população da pesquisa é de $60 \%$ de acadêmicos do sexo feminino e de $40 \%$ de acadêmicos do sexo masculino. Em um segundo apontamento, a média de idade está em 20 e 22 anos divididos em todos os semestres da graduação. Mais especificamente, $37,5 \%$ tem de 17 à 19 anos, ou seja, saíram do ensino médio e logo iniciaram uma graduação, afim de iniciar um curso de nível superior, para seguir os estudos e se formar profissionalmente.

Os jovens que ingressam na universidade confrontam-se com uma série de desafios pessoais, interpessoais, familiares e institucionais que merecem uma análise mais atenta pela IES como um todo, quanto a receptividade e auxílio na recepção desses jovens. Pois, de acordo com Sitoe (2014, p. 01), a transição "para o ensino superior é geralmente encarada como um marco muito importante, quer pelo próprio estudante, quer pela sociedade, em geral. Diferenças a nível institucional e fatores de ordem pessoal fazem com que essa transição constitua um grande desafio para o estudante".

Outra porcentagem equivalente à 17,5\% de acadêmicos pesquisados tem de 23 à 25 anos, em menor quantidade estão alunos de 25 à 30 anos, representando 2,5\% e acadêmicos que ficaram um tempo, após o Ensino médio, fora da IES e retornam para cursar uma graduação, estes, consultados da pesquisa, somam 2,5\%. Dentre estes, apenas 2,5\% dos pesquisados já fizeram alguma graduação, e os demais estão realizando o primeiro curso de nível superior. 


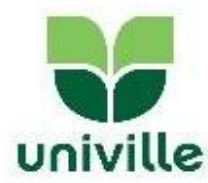

Os acadêmicos, na forma como se constitui o ensino, permanecem quase que diariamente na IES, fazendo parte da movimentação e da atividade de todos os setores de atendimento e articulação; essa movimentação e participação requer que todos os departamentos estejam alinhados receptivos para que essa estada ali, em busca de informações, documentos e pesquisa, seja benéfica. A comunicação com os acadêmicos é percebida como fator de contato e imagem e por isso deve ser fortemente valorizada conforme, verifica-se em vários questionamentos, como a IES é vista. Marchiori (2010) afirma que a comunicação, ou seja, a troca de informações é considerada um processo de construção de relações internas. Essa perspectiva possibilita novas relações organizacionais que proporcionam o desenvolvimento dos indivíduos, questão imprescindível para a sustentabilidade das organizações, assim como das IES, foco deste estudo.

Após compreender qual a situação e verificação do público pesquisado, se fez necessária uma identificação de como esse acadêmico conheceu a IES, conforme pergunta aplicada. a maior parte dos entrevistados obteve conhecimento sobre a marca da IES por indicação de amigos, sendo cerca de 35\%. Isso comprova o que salienta Morais (2015, p. 99), "pesquisas mostram que as pessoas acreditam mais em sua rede de contatos do que nas propagandas", o que firma sempre mais a importância de se bem relacionar e de passar uma boa imagem da marca, pois o vínculo e o sentimento são os fatores que fazem com que a marca seja lembrada e indicada.

Outra grande porcentagem de ingressos na IES somam $30 \%$ de acadêmicos que conheceram a IES por meio do projeto da atividade externa voltada à formação continuada de estudantes do Ensino Fundamental, Ensino Médio e Ensino Profissionalizante. Essa atividade é vista, de acordo com as respostas verificadas como assertiva, pois 57,5\% classificam como excelente e $35 \%$ classificaram como boa, essa atuação na escola, antes do ingresso, o que permite com que seja sempre evoluída e mantida essa forma de contato e vínculo, antes mesmo de ingressar IES. Referente as outras formas com que o acadêmico conheceu a IES, destaca-se as mídias sociais, com $25 \%$, após, material publicitário impresso, jornais, folders e cartazes e somente $2,5 \%$ destacaram que conheceram de outra forma.

Com base nesse resultado, é possível equiparar qual o fator que fez com que os acadêmicos pesquisados escolhessem a IES para cursar a sua graduação, e estabelecendo grande maioria, está a localização da IES, com $72,5 \%$, esta, é vista como uma forma de facilitar o aprendizado. Outros $10 \%$ dos entrevistados tem como motivo de escolha a estrutura da IES e a qualidade do ensino, essencial para retenção destes acadêmicos e da qualidade de sua formação. $\mathrm{O}$ valor das mensalidades também é um forte fator de aproximação, bem como as facilidades e benefícios aos acadêmicos ingressos.

A imagem que se cria da marca, antes de vivê-la influencia em muito a recepção e aceitação da realidade, para tanto, a expectativa em relação ao que se esperava da IES foi disposta em $80 \%$ como boa e os $10 \%$ restantes, classificaram como excelente, isso é identidade. Conforme Santos (2006) em uma IES, a marca é uma forma de caracterização da identidade. Deste modo, um acadêmico de uma IES se distingue de um aluno de outra IES em função da "marca" da instituição de ensino. Para tanto, as IES oferecem valor para os acadêmicos (SCHEE, 2011). 


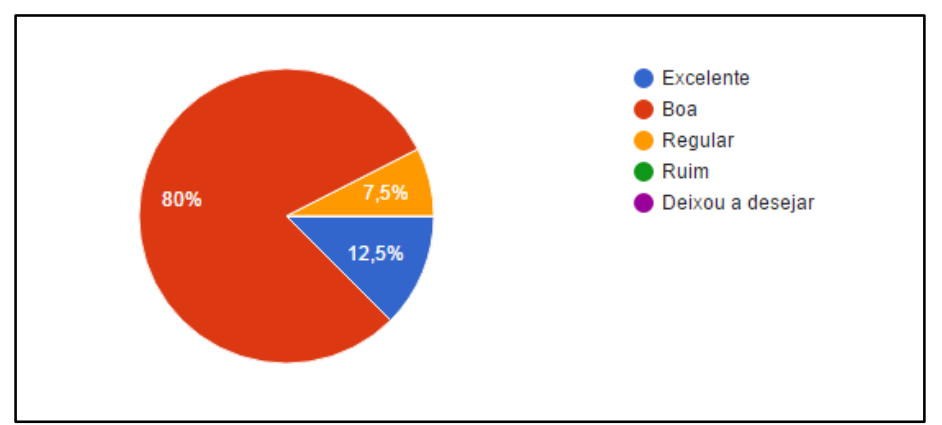

Figura 1 - Ao iniciar sua graduação as suas expectativas quanto a Instituição como um todo, referente ao que você esperava. Fonte: Os autores (2017)

Esse resultado analisado satisfaz o conjunto de ações que baseiam a identidade da instituição e reforça o que Chapleo (2007) comenta: que o convencimento do público interno é resultado de ações permanentes no sentido de uma visão clara da gestão da marca.

Da inscrição na internet ao ambiente que o acadêmico encontrará nos campus da IES, a recepção, a comunicação visual, o acesso, a formação da programação, a rede social, tudo comunica. O pós-matrícula, a conversa com os pais, o interesse, o material fornecido, os benefícios e apoios financeiros, a qualificação dos docentes e constante atualização, tudo comunica e repassa a identidade da marca e a sua percepção com o externo.

Na percepção do Mazzarol e Soutar (2008), os administradores das IES devem considerar que, enquanto as mensalidades e os elementos tangíveis podem influenciar a decisão de um estudante de frequentar uma universidade particular, os elementos intangíveis, tais como a imagem da universidade também tem uma influência significativa sobre a decisão do candidato.

Nesse caso, conforme as respostas obtidas, o relacionamento para com todas as esferas e setores é muito bem avaliada, da maneira que $47,5 \%$ classifica como boa, $45 \%$ como excelente, existe também uma quantidade significativa de acadêmicos que respondeu o relacionamento como satisfatório e apenas $2,5 \%$ afirmam ser ruim essa relação.

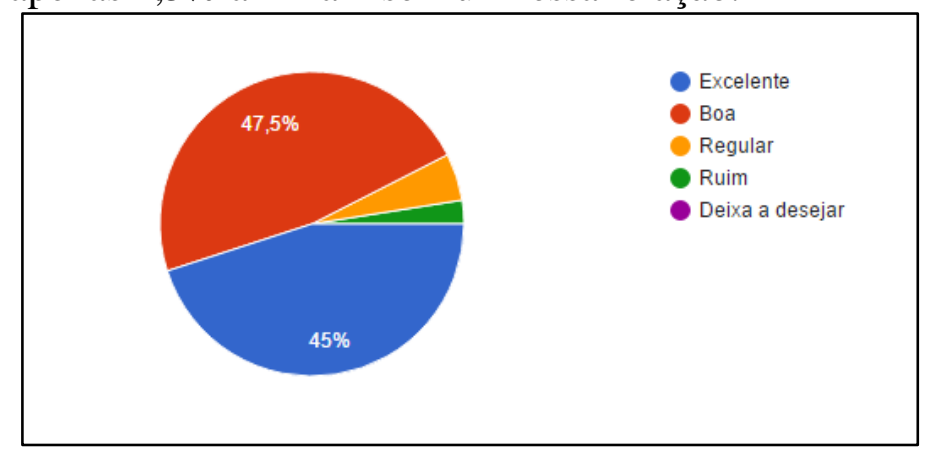

Figura 2 - O relacionamento do acadêmico com colaboradores, docentes e direção Fonte: Os autores (2017)

Mais resultados mostram como os acadêmicos avaliam as ações internas de relacionamento no que diz respeito as atividades, conversas, eventos, palestras, ações organizadas para aliar teoria e prática e trazer sempre novidades e novas modalidades de ensino. Essa gama de possibilidades é muito bem avaliada também, sendo que $22,5 \%$ alertam ser excelente o acontecimento destas, 65\% apontam como boas, $10 \%$ acreditam que estas aconteçam de forma regular no quesito resultados, e 2,5\% apenas dizem que deixa a desejar. 
O processo educacional depende em grande parte do diálogo entre professores e alunos e entre os departamentos da IES como um todo. Aliados, esses fatores são um dos principais pontos de sucesso da IES, sendo que o ensino e a educação de nível superior é 77,5\% boa, 15\% excelente e $7,5 \%$ regular.

Para análise qualitativa das demais questões, a amostragem se deu por meio da aplicação de perguntas abertas, descritivas para que o público expresse e levante dados e situações realmente importantes a serem constatadas.

De acordo com o Blog Mais Conteúdo (2016) a comunicação interdepartamental, institucional e interpessoal são imprescindíveis para o funcionamento de uma IES, além de que as mesmas devem ser levadas em consideração devido a capacidade de agregarem valor à conquista da competitividade. Dessa forma, os meios de se comunicar utilizados pela IES também dizem muito sobre a receptividade e resultados das ações. Atualmente, as mídias digitais aparecem como uma forma de relacionamento mais íntimo e prático dentro da IES. Isso foi percebido por meio do questionário o qual apontou que a maior parte dos acadêmicos pesquisa, vê e acessa as atividades pelas redes sociais para depois conferir no site da IES. O acadêmico pode conferir a qualquer momento notas, atividades, palestras e aulas, no sistema institucional, e por meio desse sistema também pode dar retorno sobre o que foi verificado.

A comunicação interna foi pesquisada de forma a compreender também não só as partes adjetivas, mas para compreender como acontece a resolução de conflitos, sugestões e problemas. A amostragem da pesquisa, respondeu a questão referindo-se a reclamações, melhorias, dúvidas, críticas e ideias, de forma que foi constatado que: alguns acadêmicos ainda não precisaram sanar problemas e os se reportar a setores para o fim de criticar; parte do público aponta como boa a resolução dos problemas, usando de palavras como interativa, eficaz, esforçada, detentora de diálogo e interesse na resolução, dispostas e acessível para explicar situações e se possível corrigir os problemas; contudo há itens a serem analisados no que se refere ao trato da coordenação do curso, o qual foi apontado, por uma minoria, de certa forma, não humilde no trato com os acadêmicos; outra análise crítica percebida foi quanto a resolução de um problema específico encaminhado para ouvidoria, o qual espera resolução. Ademais, constata-se que existe uma atenção interna institucional em não causar conflitos e gerar atritos, isso tudo colabora para um bom convívio e imagem da marca.

De modo a refletir sobre como se pode melhorar a relação e interação para com os acadêmicos, aplicou-se uma pergunta aberta indagando em o que se vê como essencial na construção do conhecimento e do desenvolvimento acadêmico, dentro da IES. Assim, as respostas apontaram tanto ideias pessoais e motivação para querer aprender, como pontos específicos de intercalação de teoria e prática, capacitação e formação da equipe docente, palestras, programas de educação continuada, inovação em técnicas de aprendizagem, estrutura física sempre em busca de melhoria; sempre em busca de diferenciais e de tornar mais atrativo o ambiente de ensino, esses apontamentos expressam o que o acadêmico percebe e almeja.

$\mathrm{O}$ acadêmico, por meio da pesquisa pode colocar o que espera que a IES possa contribuir para suas necessidades e prioridades.

Todos os apontamentos verificados podem ser comparados a sua permanência na IES, de forma que poucos encontrariam motivos para trocar ou trancar a graduação ou instituição. A retenção de alunos acontece quando os resultados e ensino focam no bem atender do público. Assim, apresentam-se alguns motivos que podem ser propulsores de evasão no ensino superior, tais como: facilidade do ensino a distância, caso não se investisse mais em laboratórios e salas interativas, professores, esporadicamente desinteressados e/ou que não saibam repassar o 
conhecimento.

Nesse sentido, condições externas são os maiores fatores de saída da IES, como mudança de cidade, egresso em Instituições Federais, dificuldades financeiras ou adversidades durante o período. É possível perceber, de acordo com uma resposta de um entrevistado, que para a região a IES veio para sanar a necessidade de se sair para longe para conquistar um ensino de qualidade, para tanto permanecer perto da família, podendo trabalhar e viver bem na sua cidade, faz com que muitos optem pela IES nessa região e se satisfaçam com o que lhes é oferecido: "Acredito que não trocaria IES por nada, pois sou muito bem atendido aqui e, além disso, eu não gostaria de sair de perto de minha família" (entrevistado).

É esse conjunto de situações, que além do feedback, fazem com que a IES evolua, sua marca cresça e seu valor intangível e reconhecimento aconteçam e os acadêmicos permaneçam por toda sua graduação na IES e sim, sigam se relacionando com a marca.

\section{CONSIDERAÇÕES FINAIS}

Compreender como as atuais ações de engajamento, atividades e relacionamento funcionam, permite contabilizar resultados e retornos futuros. Um parecer positivo, uma percepção satisfatória, propícia relacionamentos e engajamentos futuros, seja por meio de novas graduações, pós-graduações, indicações, cursos de extensão e propaganda direta da marca perante o público externo, interno e alvo, que, conforme percebido, sofre demasiadas influências pelo que ouve da IES.

Frente o contexto supracitado, nota-se a partir dos resultados obtidos, que é preciso atingir o acadêmico com opções atrativas de cursos, caminhos e estratégias pertinentes além de desenvolver conteúdos educacionais para solucionar as dificuldades que os alunos possuem durante o curso é fundamental para aumentar a retenção na IES. Quanto maior, mais próximo e desburocratizado for o atendimento a resolução ou explicação de problemas, mais satisfeitos os dois âmbitos se expressarão.

Com relação aos objetivos chega-se aos conceitos e bases da estruturação da marca da IES, no sentido da sua apresentação perante os acadêmicos e ao público externo, que se referem a, inicialmente, uma boa visualização e imagem de marca, pelo trabalho que é desenvolvido tanto nas escolas, atingindo o público-alvo, quanto nas atividades de extensão, comunitárias e de relacionamento com a comunidade.

A marca se mostra estruturada no sentido de se fazer presente de forma continuada e com comunicação focada e atrativa para os alunos, nas escolas, em atividades e apoios paralelos, antes de ingressas na faculdade, para esses futuros acadêmicos. Como percebido, as redes sociais e o site da IES são os maiores meios de visualização da marca, pela lembrança do nome, mas o que é fortalecido e comprovado pela pesquisa, é a qualidade do que é ofertado, ao verificar que a maioria dos acadêmicos teve uma primeira visualização de intenção e foi pesquisar pela IES, por indicação, seja de amigos, familiares, conhecidos formados nas áreas em que atraem os alunos, e esse contato boca-a-boca é muito válido e verdadeiro, pela confiança que passa e pela referência que é criada e vende a imagem da IES, após os resultados pessoais individuais.

Da mesma maneira, percebe-se que as necessidades e adjetivos que fazem com que os acadêmicos, optem pela IES e se relacionem com esta são em primeira verificação, o atendimento, o relacionamento do meio docente, funcionários e direção para com todas as escalas de alunos e comunidade externa que conhece e se faz presente nas atividades desta. A ligação e a atenção para sanar problemas e buscar evoluir com as críticas e trazer novos métodos 
de ensino, fazem com que a qualidade seja percebida no âmbito da retenção de alunos e na permanência destes, tanto quanto na participação das atividades IES como um todo.

A correlação da teoria com a prática, viagens, aulas interativas e de muita conversa e troca de experiências faz com que o acadêmico se sinta parte da aprendizagem e o faz buscar resultados. O nível docente e a estruturação hoje dos cursos, bem como a qualidade do ensino, agregam força ao princípio de educar na IES.

Dessa forma, considera-se que com base na literatura sobre esta temática e a partir da análise dos resultados que é necessária uma organização, identidade e gestão da marca em conjunto, para dar sequência na evolução e na captação de novos acadêmicos através do bem atender, de um fazer significado, ter relevância, ser lembrança para o acadêmico e transformar quem pela IES passou; uma evolução e ensino de qualidade que se fortaleça e reforcem os desejos de se graduar, aliados a benefícios, facilidades, bom atendimento, qualidade profissional e docente e desejo de crescer com excelência.

\section{REFERÊNCIAS}

ALMEIDA, L. S.; SOARES, A. P. Os estudantes universitários: Sucesso escolar e desenvolvimento psicossocial. Estudante universitário: Características e experiências de formação, p. 15-40, 2004.

BALDISSERA, Rudimar. Estratégia, comunicação e relações públicas. Intercom, 2001.

BENEKE, J. H. Marketing the institution to prospective students - a review of brand management in higher education. International Journal of Business and Management, $v$. 6, n. 1, p. 29-44, 2011.

BUENO, Wilson da Costa. Comunicação e gestão empresarial: cenários contemporâneos. Communicare, São Paulo, Faculdade Cásper Líbero. 2002.

COBRA, Marcos; BRAGA; Ryon. Marketing educacional: ferramentas de gestão para Instituições de ensino. São Paulo: Cobra, 2004.

COBRA, Marcos. Marketing Básico: uma perspectiva Brasileira.4.ed-9 impressão- São Paulo: Atlas 2011.

FARRUGIA, Christine A.; LANE, Jason E. Legitimacy in cross-border higher education: Identifying stakeholders of international branch campuses. Journal of Studies in International Education, v. 17, n. 4, p. 414-432, 2013.

FROHLICH, N.; STENSAKER, B. Student recruitment strategies in higher education: promoting excellence and diversity? International Journal of Educational Management, v. 24, n. 4, p. 359-370, 2010.

GARCIA, Mauricio et al. Gestão Profissional em Instituições Privadas de Ensino Superior. São Paulo: Editora Hopper, 2006.

GONÇALVES, L. C.; GARRIDO, I. L.; DAMACENA C. Proposta de um modelo conceitual 6o GAMPI Plural, 2017, Joinville, SC. 
de valor de marca na nova logica de serviços. Revista Brasileira de Gestão de Negócios, v. 12, n. 36, p. 341-357, 2010.

GUIMARÃES, Ricardo. Branding e essência de marca. Meio \& Mensagem. 2011.

HAIR, Joseph F. Análise multivariada de dados. 5. ed. Porto Alegre: Bookman, 2005.

KELLER, K. L. Building strong brands in a modern marketing communications environment. Journal of Marketing Communications, v. 15, n. 2-3, p. 139-155, 2009.

MALHOTRA, Newton. Pesquisa de marketing: uma orientação aplicada. 3 ed. Porto Alegre: Bookmark, 2001.

MARCHIORI, Marlene. Os desafios da comunicação interna nas organizações. ConexãoComunicação e Cultura, v. 9, n. 17, p. 145-159, 2010.

MARTINS, C. B. O ensino superior brasileiro nos anos 90. In: Revista São Paulo em Perspectiva. São Paulo: 2000.

Mazzarol, T. W., \& Soutar, G. N. (2008). Strategy matters: strategic positioning and performance in the education services sector. International Journal of Nonprofit and Voluntary Sector Marketing, 13, 141-151.

MELO, Eugênio Bispo. Gestão de marketing e branding: a arte de desenvolver e gerenciar marcas. Alta Books: Rio de Janeiro, 2014.

MORAIS, Felipe. Planejamento estratégico digital. São Paulo: Saraiva, 2015.

PALACIO, Asunción; MENESES, Gonzalo; PÉREZ, Pedro J. P. The configuration of the university image and its relationship with the satisfaction of students. Journal of Educational Administration, v. 40, n. 5, p. 486-505, 2002.

RAMEZANALI, Mehran; SOUZA, Maria José Barbosa de; SILVEIRA, Amelia. Os desafios da marca na instituição de ensino superior. Revista Brasileira de Marketing, v. 13, n. 3, p. 78-89, 2014.

RODRIGUES, Delano. Um breve panorama do branding. $7^{\circ}$ Congresso brasileiro de pesquisa e desenvolvimento em design - P\&D. Curitiba, 2006.

SANTOS, C. A. A. As marcas midiáticas da educação a comunicação das instituições de ensino superior privadas: imagens projetadas para a sociedade, para o mercado de trabalho e para os alunos. Tese de Doutorado em Comunicação, Escola de Comunicação da Universidade Federal de Rio de Janeiro, Rio de Janeiro, RJ, Brasil, 2006.

SILVA, Paula Bortolini; VILAÇA, Wilma Pereira Tinoco. Comunicação 
interna em Instituições de Ensino Superior. Disponível em:

<www.administradores.com.br>. Acesso em 13 de março de 2017

SCHARF, E. R.; VIEIRA, F. G. D. V.; KRAUSE, R. Estudos sobre identidade de marca: uma análise sobre a produção acadêmica brasileira de 1997 a 2011. Revista Eletrônica de Gestão Organizacional, v. 11, n. 1, p. 34-61, 2013.

SCHEE, B. A. Vander. Students as consumers: programming for brand loyalty. Services Marketing Quarterly, v. 1, n. 32, p. 32-43, 2011.

SITÓE, Arlindo. Transição do ensino secundário para o ensino superior-sugestão para uma abordagem psico-epistemológica. Revista Electrónica de Investigação e Desenvolvimento, n. 3, p. 1-16, 2014.

VIEIRA, P. R da C.; TROCCOLI, I. R.; SILVA, J. M. C. A relevância do corpo docente na qualidade percebida em serviço de ensino superior no Brasil: um estudo com modelagem de equações estruturais. Revista Economia \& Gestão, v. 11, n. 26, p. 82-109, 2011.

Blog mais conteúdo. Disponível em:

http://www.blogmaisconteudo.com.br/?s=comunica\%C3\%A7\%C3\%A3o Acesso em: 18 de março de 2017 